\title{
Influence of Successive Vagal Stimulations on Contractions in Esophageal Smooth Muscle of Opossum
}

\author{
JaSwant S. Gidda and RaJ K. Goyal, The Charles A. Dana Research Institute \\ and the Harvard-Thorndike Laboratory of Beth Israel Hospital, Department \\ of Medicine, Division of Gastroenterology, Beth Israel Hospital and Harvard \\ Medical School, Boston, Massachusetts 02215
}

\begin{abstract}
A B S T R A C T Studies were performed in anesthetized opossums to investigate the influence of successive vagal stimuli on esophageal contractions. Mechanical activity was recorded manometrically $5 \mathrm{~cm}$ above the lower esophageal sphincter. Contractions in the esophagus were evoked by electrical stimuli of $2.5 \mathrm{~mA}$, and 1-ms pulse duration applied to the cervical vagi, at various train durations and frequencies. Paired or multiple stimuli of 1-s train length were also tested at different interstimulus intervals (ISI). Paired stimuli at an ISI of $\leqslant 3 \mathrm{~s}$ and at a frequency of $\leqslant 10 \mathrm{~Hz}$ showed refractoriness, i.e., the contractions to the first stimulus inhibited the contraction to the second stimulus. A frequency of $50 \mathrm{~Hz}$ showed initial inhibition, i.e., the second stimulus inhibited the contraction to the first stimulus. Repetitive stimuli applied at a rate of $8 / \mathrm{min}$ (ISI $6.5 \mathrm{~s}$ ) evoked contractions to each stimulus. At 15/ min, every second or third contraction was inhibited. With stimuli applied at $30 / \mathrm{min}$, contractions occurred only in response to the first and/or the last stimulus; depending upon the frequency of vagal stimulation. The intervening stimuli did not evoke any contractions. A long train stimulus produced an initial, a terminal, or both contractions depending on the stimulation value. These studies show that $(a)$ vagal efferent stimulation causes initial inhibition and refractoriness in the esophageal smooth muscle; $(b)$ the degree of initial inhibition increases with increasing frequency of stimulation; $(c)$ the occurrence of contractions only at the onset and the end of a long train stimulus may be due to the influence of initial inhibition and refractoriness.
\end{abstract}

Address all correspondence to Dr. R. K. Goyal, Gastroenterology Division, Beth Israel Hospital, Boston, MA 02215.

Received for publication $27 \mathrm{July} 1982$ and in revised form 8 November 1982.

\section{INTRODUCTION}

Swallowing or vagal efferent stimulation with $<1-s$ train are followed by a wave of contraction in the esophageal body (1-5). Repetitive swallowing at short intervals, as occurs during drinking of liquids, produces an esophageal response characterized by quiescence until the last of the swallows, which is then followed by an esophageal contraction (6-8). Meyer et al. (7) have also shown that two or more swallows taken in rapid succession may markedly influence the response to the preceding swallows.

In experimental animals, vagal efferent stimulations with long train durations show an intriguing pattern of esophageal response. Dodds et al. (4) reported that stimulation with long trains (e.g., $8 \mathrm{~s}$ ) evoked esophageal contractions that occurred either after the beginning (A-contraction) or the end (B-contraction) of the stimulus train. At low frequencies of stimulation it occurred only at the beginning of the stimulus whereas at high frequencies of vagal stimulation, the contraction was seen only at the end of the stimulus train. Interestingly, the esophagus remained relatively quiescent during the intervening period despite ongoing vagal stimulation. This interesting phenomenon remains unexplained.

The purpose of this study was to investigate the influence of two or more closely applied vagal stimuli on esophageal responses. Our studies show that esophageal contractions evoked by vagal stimulation are bordered by two inhibitory phenomena: initial inhibition and refractoriness. These findings explain the esophageal responses to repetitive swallowing and contractions occurring only at the onset and the end of long train vagal stimulation.

\section{METHODS}

Experimental procedure. Studies were performed in 17 adult opossums (Didelphis virginiana) of either sex weighing

J. Clin. Invest. (C) The American Society for Clinical Investigation, Inc. • 0021-9738/83/05/1095/09 $\$ 1.00$ 
from 2.2 to $4.6 \mathrm{~kg}$. The animals were fasted for $14-16 \mathrm{~h}$ before they were anesthetized with a $40 \mathrm{mg} / \mathrm{kg}$ i.p. injection of pentobarbital sodium. The anesthesia was maintained as needed with $5 \mathrm{mg} / \mathrm{kg}$ of pentobarbital administered intravenously through a cannula in the brachial vein. The animals were strapped supine on an animal board. Respiration was supported with a mechanical respirator (Harvard Apparatus, Co., Inc., S. Natick, MA) that pumped room air at 20 strokes/ min. The body temperature was maintained at $37^{\circ} \mathrm{C}$ with a heating pad placed beneath the animal. Intraluminal esophageal pressures were monitored at $5 \mathrm{~cm}$ above the lower esophageal sphincter (LES) ${ }^{1}$ with a water-filled and continuously perfused catheter assembly as described previously (9) and recorded on a Beckman Dynograph recorder (R411, Beckman Instruments, Inc., Fullerton, CA) using Statham pressure transducers (model P23db, Statham Instruments, Inc., Oxnard, CA). The catheter assembly was introduced transorally into the stomach and then withdrawn gradually at $2-\mathrm{mm}$ intervals to scan the high pressure zone of the LES. The assembly was then positioned so that the most distal hole was in the middle of the LES. The assembly was then anchored by inserting a pin through the esophageal wall and the central core tubing of the catheter assembly as described previously (9). The vagi were identified in the neck and sectioned. The cut peripheral end of one of the vagi was stimulated with square wave pulses of $2.5-\mathrm{mA}$ current intensity and 1-ms pulse duration. In six animals vagal efferents were stimulated with continuous trains stimuli of $1-60$-s duration at 5,10 , and $50 \mathrm{~Hz}$. In 11 animals, one of the vagi was stimulated with paired and multiple repetitive stimuli of 1-s duration. Paired 1-s trains were separated by varying the time interval between two trains from 0.1 to 10 s. The time interval between two train stimuli is called interstimulus interval (ISI). The multiple repetitive trains were given at a rate of $8,10,12,15,30$, or $60 / \mathrm{min}$. The $60 / \mathrm{min}$ was a continuous 1 -min train stimulus. In 3 out of 11 animals stimulus frequencies of 5,10 , and $50 \mathrm{~Hz}$ were also tested at each ISI or stimulus rate. At the end of each experiment the animal was killed with a lethal dose of the anesthetic.

Data analysis. Pressure waves evoked by vagal efferent stimulation were analyzed for amplitude $(\mathrm{mmHg})$ and latency (seconds) of response. Response latency was measured from the onset of the stimulus to the onset of the pressure wave. When a second contraction was evoked with long train stimuli, its latency was measured from the onset as well as from the termination of the stimulus. The latency data were used to determine the relationship between the stimulus and response. For example, when a paired stimulus train at a short ISI ( $\leqq 2 \mathrm{~s}$ ) evoked only one response, the latency of this response from the onset of the first and second stimulus was determined and compared with the latency of response when only one stimulus was given. If the response belonged to the first stimulus in the pair then its latency was similar to that obtained with one stimulus. For averaging multiple abolished responses were considered to be of $0 \mathrm{~mm} \mathrm{Hg}$ amplitude. Data were analyzed using analysis of variance (10). Significance of difference was determined using the Duncan test. Significance of difference between the A and B-response latency and amplitude was determined using the unpaired $t$ test. Significance of difference between the number of $A$ and $B$ responses evoked by various train durations was determined by chi $^{2}$ test $(10)$.

${ }^{1}$ Abbreviations used in this paper: ISI, interstimulus interval; LES, lower esophageal sphincter.

\section{RESULTS}

Esophageal contractions to stimulation of vagal efferents at different train lengths. Vagal efferent stimulation with 2.5-mA current intensity, 1-ms pulse duration, and a frequency of $10 \mathrm{~Hz}$ evoked either one or two contractions to each stimulus train of $1 \mathrm{~s}$ or longer duration, as shown in Fig. 1. Whether one or two contractions were evoked depended on the duration of the train length. Short trains, e.g., 1 or 2.5 $\mathrm{s}$ evoked only one contraction. Train durations of $5 \mathrm{~s}$ or longer evoked a second contraction that occurred after a latency from the offset of the stimulus. When two contractions were present, the first contraction resembled in latency and other characteristics, to the only response that occurred at short stimulus trains (Table I).

Table II shows the influence of train duration on the occurrence and amplitude of contractions. The data show that a train duration of $4 \mathrm{~s}$ or less evoked only one contraction. This response was evoked by $>80 \%$ of stimuli at all train durations. The second contraction at 5- and 8-s train duration was present 41 and $66 \%$ of the time, respectively. Both contractions were present $>\mathbf{7 5 \%}$ of the time, when stimulus train duration was $10 \mathrm{~s}$ or longer.

The amplitude of the first (A) contraction was not

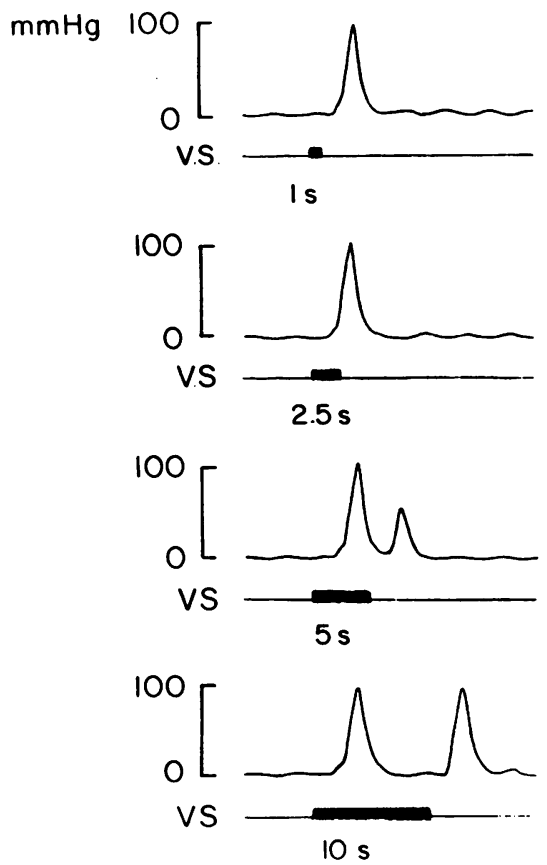

FIGURE 1 Influence of stimulus train duration on esophageal contraction at $5 \mathrm{~cm}$ above LES. Note that short trains of 1 and $2.5 \mathrm{~s}$ produce only one contraction. However, longer trains of 5 and $10 \mathrm{~s}$ produce two contractions (A and $B$ ). Other stimulus parameters: $2.5 \mathrm{~mA}, 1 \mathrm{~ms}$, and $10 \mathrm{~Hz}$. 
TABLE I

Influence of Stimulus Train Duration on the Number of Contractions and Their Relation to the Onset and Offset of the Stimulus

\begin{tabular}{|c|c|c|c|c|c|c|}
\hline \multirow{3}{*}{$\begin{array}{c}\text { Train } \\
\text { duration }\end{array}$} & \multirow{3}{*}{$\begin{array}{c}\text { No. of } \\
\text { observations }\end{array}$} & \multirow{3}{*}{$\begin{array}{c}\text { No. of } \\
\text { contractions }\end{array}$} & \multirow{2}{*}{\multicolumn{2}{|c|}{$\frac{A(\text { on) response }}{\begin{array}{c}\text { Latency of response from } \\
\text { stimulus }\end{array}}$}} & \multicolumn{2}{|c|}{ B (off) response } \\
\hline & & & & & \multicolumn{2}{|c|}{ Latency of response from stimulus } \\
\hline & & & Onset & Offset & Onset & Offset \\
\hline 1 & 14 & 1 & $2.1 \pm 0.1$ & $1.1 \pm 0.4$ & \multicolumn{2}{|c|}{ Not present } \\
\hline 2.5 & 13 & 1 & $2.0 \pm 0.08$ & None & \multicolumn{2}{|c|}{ Not present } \\
\hline 4.0 & 12 & 1 & $2.1 \pm 0.1$ & None & \multicolumn{2}{|c|}{ Not present } \\
\hline 5.0 & 12 & 2 & $2.1 \pm 0.08$ & None & $6.8 \pm 0.08$ & $1.8 \pm 0.08$ \\
\hline 8.0 & 12 & 2 & $2.0 \pm 0.06$ & None & $10.0 \pm 0.1$ & $2.0 \pm 0.1$ \\
\hline 10.0 & 12 & 2 & $2.1 \pm 0.1$ & None & $11.3 \pm 0.1$ & $1.3 \pm 0.1^{\bullet} t$ \\
\hline 20.0 & 12 & 2 & $2.0 \pm 0.1$ & None & $21.2 \pm 0.08$ & $1.2 \pm 0.08^{\circ}$ \\
\hline 30.0 & 11 & 2 & $1.9 \pm 0.08$ & None & $31.1 \pm 0.1$ & $1.1 \pm 0.1^{\bullet}$ \\
\hline 60.0 & 12 & 2 & $2.0 \pm 0.1$ & None & $61.3 \pm 0.1$ & $1.3 \pm 0.1^{\bullet}$ \\
\hline
\end{tabular}

Values are mean $\pm \mathrm{SE}$. Vagal efferents were stimulated with $2.5 \mathrm{~mA}, 1-\mathrm{ms}$ pulse, and $10 \mathrm{~Hz}$; contractions were observed at $5 \mathrm{~cm}$ above the LES.

- Significantly different from the onset of A-response $(P<0.01)$.

† Significantly different from the B-response latency of 8-s train duration $(P<0.01)$.

Note that with the stimulus parameters used, the responses observed with 1-4 s were A-contraction, as their latencies, when calculated from the onset of the stimulus were similar to responses observed with longer train stimulations.

significantly influenced by train duration $(P>0.05)$. However, the amplitude of the second contraction (B) progressively increased with an increase in train du-

TABLE II

Occurrence and Amplitude of Contractions Produced at $5 \mathrm{~cm}$ Above LES by Vagal Efferent Stimulation at Different Train Durations

\begin{tabular}{|c|c|c|c|c|c|}
\hline \multirow{3}{*}{$\begin{array}{c}\text { Train } \\
\text { duration }\end{array}$} & \multirow{3}{*}{$\begin{array}{c}\begin{array}{c}\text { No. of } \\
\text { observation }\end{array}\end{array}$} & \multicolumn{4}{|c|}{ Responses evoked } \\
\hline & & \multicolumn{2}{|c|}{ Number } & \multicolumn{2}{|c|}{ Amplitude } \\
\hline & & $\mathbf{A}$ & B & $\mathbf{A}$ & B \\
\hline 3 & & & & \multicolumn{2}{|c|}{$m m H g$} \\
\hline 1 & 14 & 13 & $\mathbf{0}$ & $83.4 \pm 2.6$ & $0^{\bullet} \downarrow$ \\
\hline 2.5 & 13 & 12 & 0 & $89.4 \pm 2.1$ & $0^{\bullet} \pm$ \\
\hline 4.0 & 12 & 10 & 0 & $82.6 \pm 3.8$ & $0^{\circ} t$ \\
\hline 5.0 & 12 & 11 & 5 & $79.6 \pm 4.4$ & $32.0 \pm 2.6^{\circ}$ \\
\hline 8.0 & 12 & 11 & 8 & $81.4 \pm 2.8$ & $58.6 \pm 3.6^{\circ}$ \\
\hline 10.0 & 12 & 11 & 9 & $86.5 \pm 3.6$ & $84.8 \pm 2.2 \downarrow$ \\
\hline 20.0 & 12 & 11 & 12 & $90.0 \pm 2.4$ & $92.6 \pm 2.4$ \\
\hline 30.0 & 11 & 11 & 11 & $89.1 \pm 2.6$ & $96.8 \pm 3.3$ \\
\hline 60.0 & 12 & $10 \$$ & $12 \$$ & $86.4 \pm 4.9$ & $91.2 \pm 2.4$ \\
\hline
\end{tabular}

Values are mean $\pm \mathrm{SE}$. Other stimulus parameters $2.5 \mathrm{~mA}, 1-\mathrm{ms}$ pulse duration, and $10 \mathrm{~Hz}$.

- Significantly different from the amplitude of A-response $(P$ $<0.01$ ).

t Significantly different from train duration of $20 \mathrm{~s}$ or more $(P<0.01)$.

$\$$ Values in column $\mathrm{A}$ are significantly different from those in column B $\left(P<0.01\right.$; determined by chi $^{2}$ test $)$. ration from 5 to $20 \mathrm{~s}$. Trains of $20 \mathrm{~s}$ or longer failed to increase the amplitude of this contraction significantly $(P>0.05)$.

Esophageal contractions to 10-s train stimuli at different frequencies. Train durations of $10 \mathrm{~s}(2.5$ $\mathrm{mA}, 1 \mathrm{~ms}$ ) at $10 \mathrm{~Hz}$ produced two contractions, each appearing after a certain latency from the onset (A or on) and offset (B or off) of the stimulus (Fig. 2). Table III shows that the occurrence and the amplitude of these two contractions at $10 \mathrm{~Hz}$ was not significantly different $(P>0.05)$. A decrease in the frequency of stimulation to $5 \mathrm{~Hz}$ evoked only one A-contraction and failed to evoke a B-contraction at the end of the stimulus. An increase in frequency to $50 \mathrm{~Hz}$ inhibited the first A-contraction significantly or completely abolished it $(P<0.01)$.

Influence of two successive stimuli on esophageal contractions. As shown in Fig. 3A (top row) paired 1-s train stimuli of $2.5 \mathrm{~mA}, 1 \mathrm{~ms}, 10 \mathrm{~Hz}$ at an ISI of $4 \mathrm{~s}$ evoked a contraction $\left(R_{1}, R_{2}\right)$ to each stimulus in the pair $\left(S_{1}, S_{2}\right)$. As shown in Table IV, the amplitude of both contractions $\left(R_{1}\right.$ and $\left.R_{2}\right)$ at an ISI of $4 s$ or longer was not significantly different $(P>0.05)$. However, at shorter ISI the response to the first stimulus $\left(R_{1}\right)$ influenced the response $\left(R_{2}\right)$ to the second stimulus. For example, at an ISI of 2-3 s $\left(\mathbf{R}_{2}\right)$ was significantly inhibited $(P<0.01)$. At an ISI of $1 \mathrm{~s}$ or less $\left(R_{2}\right)$ was completely abolished.

When stimuli of higher frequency were used, e.g., $50 \mathrm{~Hz}$, then at an ISI of $4 \mathrm{~s}$ or longer each train in the 

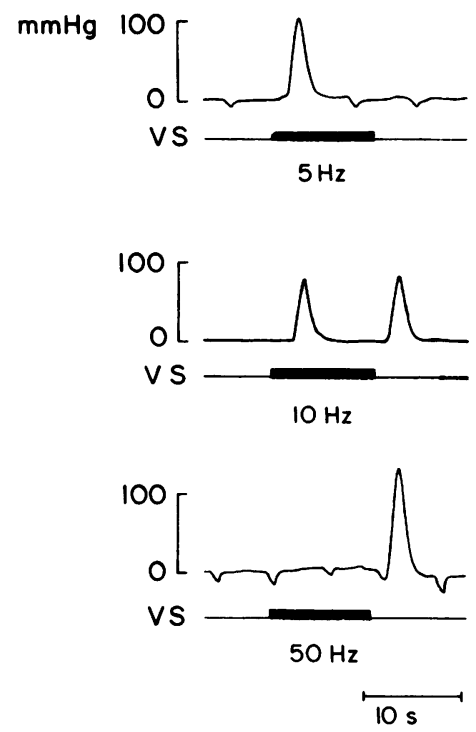

Figure 2 Influence of stimulation frequency on A and B contraction. Train duration, current intensity, and pulse duration were held constant at $10 \mathrm{~s}, 2.5 \mathrm{~mA}$, and $1 \mathrm{~ms}$, respectively. Note that the $5-\mathrm{Hz}$ stimulus evoked only A-contraction whereas $50-\mathrm{Hz}$ stimulus evoked only a B-contraction.

pair evoked contraction (Fig. $3 \mathrm{~B}$ and Table V). The amplitude of both contractions $\left(R_{1}, R_{2}\right)$ was not significantly different $(P>0.05)$. At short ISI, e.g., ISI of $3 \mathrm{~s}$ or less, the response $\left(R_{1}\right)$ to the first stimulus was either significantly inhibited $(P<0.01)$ or completely abolished (i.e., at an ISI of $0.1 \mathrm{~s}$ ). This inhibition was not identified at stimulus frequencies of $10 \mathrm{~Hz}$ or less.

TABLE III

Occurrence and Amplitude of A (On) and/or B (Off) Contraction at $5 \mathrm{~cm}$ Above LES Due To 10-s Trains of Vagal Efferent Stimulation at Different Frequencies

\begin{tabular}{|c|c|c|c|c|c|}
\hline \multirow{3}{*}{$\begin{array}{c}\text { Vagal } \\
\text { stimulation }\end{array}$} & \multirow{3}{*}{$\begin{array}{c}\text { No. of } \\
\text { olsservations }\end{array}$} & \multicolumn{4}{|c|}{ Respomses evoked } \\
\hline & & \multicolumn{2}{|c|}{ Numlxer } & \multicolumn{2}{|c|}{ Amplitude } \\
\hline & & A & B & A & B \\
\hline $\mathrm{Hz}$ & & & & \multicolumn{2}{|c|}{$m m / I g$} \\
\hline 5 & 12 & 10 & 0 & $68.4 \pm 2.3$ & $0^{\circ} \S$ \\
\hline 10 & 11 & 11 & 9 & $86.5 \pm 3.6$ & $74.8 \pm 2.2$ \\
\hline 50 & 12 & 3 & 12 & $6.5 \pm 1.81$ & $92.6 \pm 3.8^{\circ}$ \\
\hline
\end{tabular}

Values are mean $\pm \mathrm{SE}$. Other stimulus parameters $2.5 \mathrm{~mA}, 1-\mathrm{ms}$ pulse duration.

- Significantly different from A-response $(P<0.01)$.

\ Significantly different from responses at 5 and $10 \mathrm{~Hz}(P<0.01)$. $\S$ Significantly different from responses at 10 and $50 \mathrm{~Hz}(P<0.01)$.
A
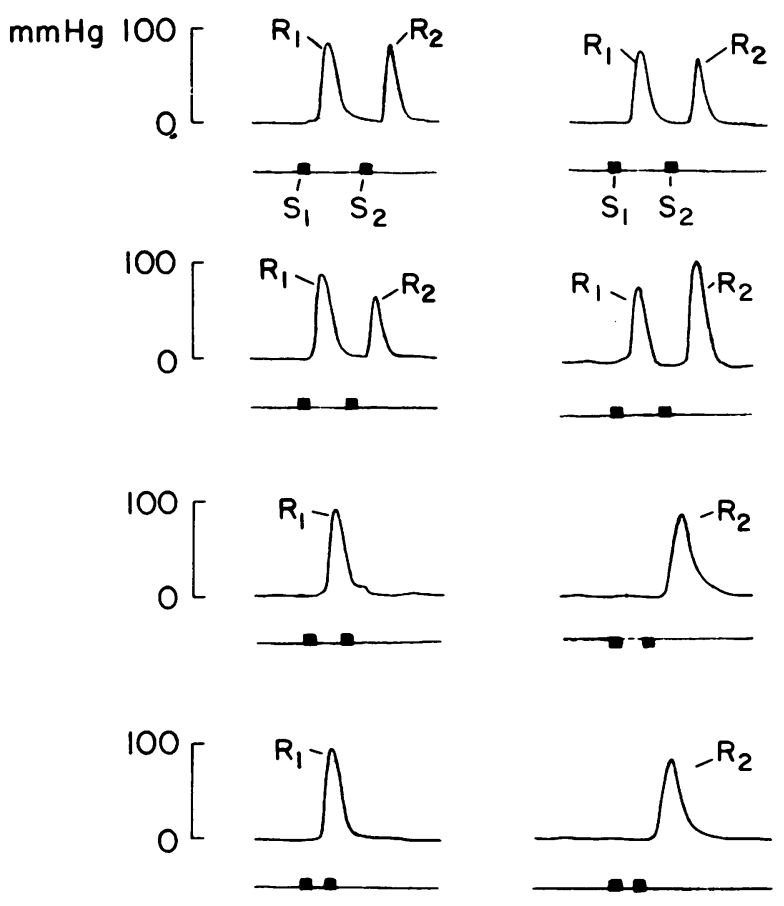

${ }_{0}^{100}[$

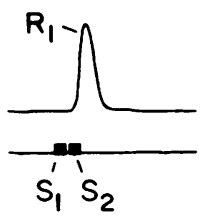

Figure 3 Esophageal responses at $5 \mathrm{~cm}$ above the LES to two successive vagal efferent stimulations at $10 \mathrm{~Hz}$ and 50 $\mathrm{Hz}$ for different ISI. Other stimulus parameters, e.g., current intensity, pulse and train duration, were kept constant at 2.5 $\mathrm{mA}, 1 \mathrm{~ms}$, and $1 \mathrm{~s}$, respectively. $S_{1}, S_{2}$ stimulus 1 and stimulus 2 , respectively. VS, vagal stimulation. Note that decreasing the time interval between two stimuli (ISI) inhibited and then abolished the second response $\left(R_{2}\right)$ at $10 \mathrm{~Hz}$. However, at a higher stimulus frequency, $50 \mathrm{~Hz}$, decreasing the ISI inhibited and then abolished the first response $\left(R_{1}\right)$.

Esophageal responses to repetitive stimulation of vagal efferents. Fig. 4 shows contractions evoked by repetitive 1-s train stimuli of $2.5 \mathrm{~mA}, 1-\mathrm{ms}$ pulse duration and a frequency of $10 \mathrm{~Hz}$. The successive stimuli were applied for $1 \mathrm{~min}$ at different train rates. When the train rate was $8 / \mathrm{min}$, each train stimulus evoked a contraction. As shown in Table VI, the amplitude of these contractions was not significantly different $(P$ $>0.05$ ). However, when the stimulus rate was increased to $12 / \mathrm{min}$, the successive responses were significantly reduced in amplitude $(P<0.01)$. At a train rate of $15 / \mathrm{min}(\mathrm{ISI}=3 \mathrm{~s}$ ) alternate responses were sig- 
TABLE IV

Influence of Response to the First Stimulus $\left(R_{1}\right)$ on the Occurrence and Amplitude of Response to the Second Stimulus $\left(R_{2}\right)$ at Different ISI

\begin{tabular}{|c|c|c|c|c|c|}
\hline \multirow[b]{3}{*}{ ISI } & \multirow{3}{*}{$\begin{array}{c}\text { No. of } \\
\text { observations }\end{array}$} & \multicolumn{4}{|c|}{ Responses evoked } \\
\hline & & \multicolumn{2}{|c|}{ Numlxer } & \multicolumn{2}{|c|}{ Amplitude } \\
\hline & & $\mathbf{R}_{\mathbf{1}}$ & $\mathrm{R}_{2}$ & $\mathbf{R}_{1}$ & $\mathbf{R}_{2}$ \\
\hline$s$ & & & & \multicolumn{2}{|c|}{$m m H g$} \\
\hline 0.1 & 43 & 43 & 0 & $96.8 \pm 3.9$ & $0^{\circ}$ \\
\hline 1.0 & 42 & 42 & 0 & $81.9 \pm 2.2$ & $0^{\circ}$ \\
\hline 2.0 & 42 & 40 & 5 & $100.5 \pm 4.3$ & $14.7 \pm 1.8^{\circ}$ \\
\hline 3.0 & 42 & 42 & 15 & $96.7 \pm 3.9$ & $32.2 \pm 2.1^{\circ} t$ \\
\hline 4.0 & 42 & 41 & 38 & $98.9 \pm 1.8$ & $94.3 \pm 1.2 \ddagger$ \\
\hline 5.0 & 42 & 41 & 37 & $96.2 \pm 2.8$ & $93.8 \pm 2.2$ \\
\hline 6.0 & 42 & 42 & 42 & $101.4 \pm 2.9$ & $100.5 \pm 3.1 \rrbracket$ \\
\hline 7.0 & 42 & $42 \S$ & $42 \S$ & $103.3 \pm 3.1$ & $103.2 \pm 2.9$ \\
\hline
\end{tabular}

Values are mean $\pm \mathrm{SE}$. Each individual stimulus was of 1-s train, $2.5 \mathrm{~mA}, 1-\mathrm{ms}$ pulse duration, and $10 \mathrm{~Hz}$.

- Significantly different from $R_{1}(P<0.01)$.

† Significantly different from $R_{2}$ at next lower ISI $(P<0.01)$.

$\$$ Values in column $R_{1}$ are significantly different from those in column $\mathbf{R}_{2}\left(P<0.01\right.$; determined by $\mathrm{chi}^{2}$ test). At short ISI, when only one response was observed it was based upon the similarity of its temporal relationship to the first or second stimulus (Fig. 3A).

nificantly inhibited $(P<0.01)$ or abolished (Fig. 4 and Table VI). An increase in stimulus rate to $30 / \mathrm{min}$ (ISI $=1 \mathrm{~s}$ ) evoked contraction only to the first and last stimulus. The intervening stimuli either failed to evoke a response or occasionally produced significantly small amplitude responses (Table VI). A stimulus rate of 60/ min, which is a continuous 1-min train stimulus, evoked A and B responses similar to responses to first and the last stimuli applied at a rate of $30 / \mathrm{min}$.

As shown in Fig. 5 and Table VII, repetitive 1-s stimuli at $50 \mathrm{~Hz}$, produced near normal contractions with each stimulus when the stimulus rate was $8 / \mathrm{min}$. However, at a train rate of $12 / \mathrm{min}$ the succeeding responses were inhibited. In some instances there were two responses of equal amplitude and the third response was absent. At other times alternate responses were abolished and the remaining responses were inhibited. When the stimulus rate was increased to 15/ min or more (Table VII) there was no response to the first or any subsequent stimuli except the last one. Rarely, small amplitude responses to the intermediate stimuli were also observed. With a continuous 1-min stimulation at a stimulus rate of $30 / \mathrm{min}$, only a Bresponse at the end of the stimulus was observed. This B-response was similar to the response to the last stimulus when stimuli were applied at a rate of 15 or 30 / min. Quantitative data on the amplitude of the first, last, and intermediate six contractions are shown in Table VII.

\section{DISCUSSION}

These studies show that an esophageal contraction in response to vagal stimulation is bordered by two inhibitory phenomena: initial inhibition and refractoriness. Experimental circumstances that reveal these two inhibitory phenomena are, however, different.

The phenomenon of initial inhibition refers to inhibition of any activity in the esophagus that may be occurring at the time of vagal stimulation. The degree of initial inhibition increases with increasing frequency of stimulation. Therefore, this phenomenon is best demonstrated when two short train stimuli of high frequency are applied closely together. The genesis of initial inhibition is not well defined, however, it may be related to hyperpolarization of smooth muscle membrane that precedes its depolarization and spike burst (3).

The phenomenon of refractoriness refers to inhibition of any evoked contraction that may tend to occur during and soon after the ongoing esophageal response to a previous stimulus. This phenomenon can be demonstrated only at low frequencies of stimulation when the initial inhibition is not marked. Experimentally it is shown when the response to a preceding stimulus is normal but the response to a following stimulus is

TABLE V

Influence of Second Stimulus $\left(S_{2}\right)$ on the Inhibition of Response to the First Stimulus $\left(R_{1}\right)$ at Different ISI at $5 \mathrm{~cm}$ Above LES

\begin{tabular}{|c|c|c|c|c|c|}
\hline \multirow{3}{*}{$\begin{array}{l}\text { Interstimulus } \\
\text { interval (ISI) }\end{array}$} & \multirow{3}{*}{$\begin{array}{c}\text { No. of } \\
\text { observations }\end{array}$} & \multicolumn{4}{|c|}{ Responses evoked } \\
\hline & & \multicolumn{2}{|c|}{ Number } & \multicolumn{2}{|c|}{ Amplitude } \\
\hline & & $\mathbf{R}_{\mathbf{1}}$ & $\mathbf{R}_{2}$ & $\mathbf{R}_{1}$ & $\mathbf{R}_{2}$ \\
\hline$s$ & & & & \multicolumn{2}{|c|}{$m m H g$} \\
\hline 0.1 & 14 & 0 & 14 & 0 & $92.8 \pm 3.9^{\circ}$ \\
\hline 1.0 & 14 & 3 & 14 & $6.1 \pm 0.6 \ddagger$ & $96.2 \pm 4.8^{\circ}$ \\
\hline 2.0 & 14 & 3 & 14 & $4.2 \pm 0.6$ & $94.9 \pm 2.6^{\circ}$ \\
\hline 3.0 & 14 & 4 & 14 & $6.7 \pm 0.9$ & $89.4 \pm 4.8^{\circ}$ \\
\hline 4.0 & 12 & 10 & 12 & $88.3 \pm 3.8 \ddagger$ & $92.3 \pm 3.4$ \\
\hline 5.0 & 14 & $13 \S$ & $14 \S$ & $98.8 \pm 2.2 \rrbracket$ & $96.8 \pm 4.4$ \\
\hline
\end{tabular}

Values are mean \pm SE. Each individual stimulus was of 1-s train, $2.5 \mathrm{~mA}, 1-\mathrm{ms}$ pulse duration, and $50 \mathrm{~Hz}$.

- Significantly different from $R_{1}(P<0.01)$.

I Significantly different from the response at lower ISI $(P<0.01)$. $\$$ Values in column $R_{1}$ are significantly different from those in column $\mathbf{R}_{2}\left(P<0.01\right.$; determined by $\mathrm{chi}^{2}$ test $)$. At short ISI when only one response was observed it was designated as $R_{1}$ or $R_{2}$ based upon the similarity of its temporal relationship to the first or the second stimulus (Fig. 3B). 


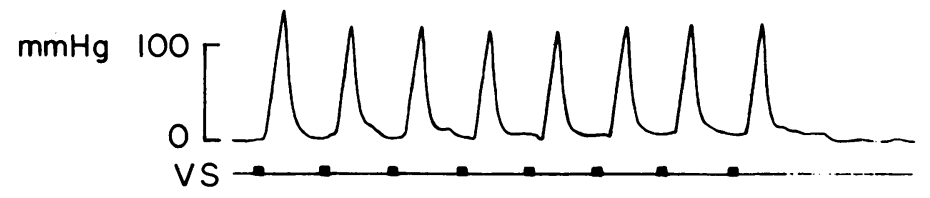

( 8 per minute)

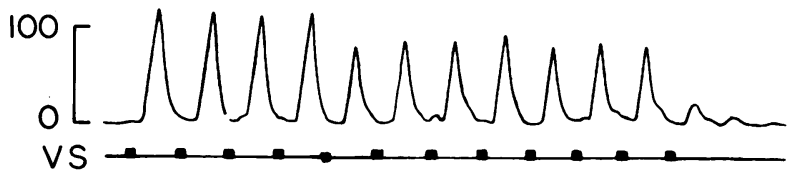

(12 per minute)

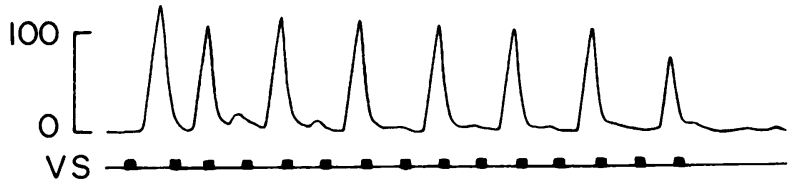

(15 per minute)

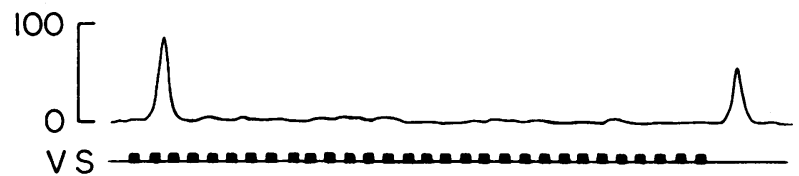

( 30 per minute)

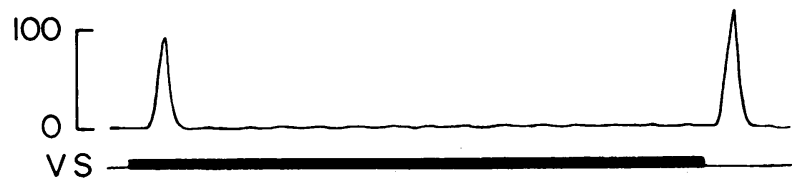

(60 per minute)

Figure 4 Influence of repetitive vagal efferent stimulation with $10 \mathrm{~Hz}$ on esophageal contractions. Other stimulus parameters $(2.5 \mathrm{~mA}, 1 \mathrm{~ms}, 1-\mathrm{s}$ train). Note that at stimulus rates of $8 / \mathrm{min}$ each stimulus evoked a response. However, at higher stimulus rates $(12 / \mathrm{min})$ the subsequent contractions were partially inhibited or the alternate responses disappeared (at 15/ $\min )$, and then all responses between the first and last were abolished $(30 / \mathrm{min}$ or more). Continuous stimulation (or $60 / \mathrm{min}$ ) produced only the first and the last response.

inhibited. The electrophysiological basis of refractoriness is not known.

Initial inhibition and refractoriness may explain esophageal responses to long train and repetitive vagal stimulations or swallows. The occurrence of contractions only at the onset or the end of a long train stimulus is explained by these studies as follows: A long train stimulus can be assumed as individual short trains applied successively at very short intervals. The A-contraction at the onset represents response to the hypothetical first stimulus, whereas the B-contraction at the end represents response to the last stimulus. This hypothesis is supported by the similarities of responses to a continuous long stimulation and multiple repetitive stimuli applied at $1 \mathrm{~s}$ apart. When the trains are of low frequency, esophageal contraction occurs to the hypothetical first short train stimulus and the responses to all the succeeding trains are inhibited because of the refractoriness. Therefore, at low frequency vagal stimulation contraction is observed only at the onset of the long train stimulus. On the other hand, when the trains are of high frequency of stimulation, the initial inhibition predominates. Therefore, responses to all the preceding stimuli are inhibited by the following stimuli. The response then occurs only to the last of the "hypothetical" 1-s stimulus train. With intermediate frequencies of stimulation contractions occur both at the onset and the end of the stimulus train. According to this formulation, therefore, the esophageal quiescence after the A- and before the B-contraction represent active inhibition and/or refractoriness of the esophagus. 
TABLE VI

Influence of Successive 1-s Train Duration (2.5 mA, 1-ms Pulse Duration, at $10 \mathrm{~Hz}$ ) Stimuli on Esophageal Contractions at $5 \mathrm{~cm}$ Above LES, at Different Stimulus Rates

\begin{tabular}{|c|c|c|c|c|c|c|c|c|}
\hline \multirow{3}{*}{$\begin{array}{l}\text { Stimulus rate } \\
\text { per minute }\end{array}$} & \multirow{3}{*}{$\begin{array}{c}\text { No. of } \\
\text { olservations }\end{array}$} & \multicolumn{7}{|c|}{ Amplitude of different contractions ( $\mathrm{mmHg}$ ) } \\
\hline & & \multirow[b]{2}{*}{ First } & \multicolumn{5}{|c|}{ Intermediate } & \multirow[b]{2}{*}{ Last } \\
\hline & & & 2 & 3 & 4 & 5 & 6 & \\
\hline $\begin{array}{c}8 \\
\text { (ISI, } 6.5 \mathrm{~s})\end{array}$ & 12 & $119.6 \pm 3.8$ & $114.2 \pm 2.2$ & $115.6 \pm 2.3$ & $112.3 \pm 2.4$ & $111.8 \pm 3.9$ & $112.6 \pm 2.4$ & $112.8 \pm 3.2$ \\
\hline $\begin{array}{c}10 \\
(\mathrm{ISI}, 5 \mathrm{~s})\end{array}$ & 15 & $116.4 \pm 3.6$ & $113.8 \pm 2.1$ & $108.5 \pm 2.1^{\circ} \downarrow$ & $100.8 \pm 3.6^{\circ} \downarrow$ & $\left.102.6 \pm 2.4^{\circ}\right\rfloor$ & $\left.98.8 \pm 2.1^{\circ}\right\rfloor$ & $104.2 \pm 2.9^{\circ} \downarrow$ \\
\hline $\begin{array}{c}12 \\
(\text { ISI, } 4 \mathrm{~s})\end{array}$ & 12 & $111.6 \pm 2.1 \ddagger$ & $101.2 \pm 1.4^{\circ} \ddagger$ & $91.2 \pm 2.2^{\bullet} \pm$ & $92.6 \pm 1.9^{\circ} t$ & $86.2 \pm 1.7^{\circ} \downarrow$ & $76.3 \pm 2.8^{\circ} \downarrow$ & $77.8 \pm 3.2^{\circ} \ddagger$ \\
\hline $\begin{array}{r}15 \\
(\mathrm{ISI}, 3 \mathrm{~s})\end{array}$ & 12 & $110.8 \pm 1.2 \downarrow$ & $22.6 \pm 2.1^{\circ} \ddagger$ & $81.2 \pm 2.9^{\circ} \ddagger$ & $15.4 \pm 1.2^{\bullet} \ddagger$ & $83.6 \pm 2.2^{\circ} \downarrow$ & $19.8 \pm 1.2^{\circ} \ddagger$ & $91.2 \pm 2.8^{\circ} \ddagger$ \\
\hline $\begin{array}{r}30 \\
\text { (ISI, } 1 \text { s) }\end{array}$ & 12 & $105.2 \pm 2.8 \rrbracket$ & $1.3 \pm 0.7^{\circ} \downarrow$ & $2.8 \pm 0.6^{\bullet} \downarrow$ & $0 \pm 0^{\circ} 1$ & $3.2 \pm 0.8^{\circ} \downarrow$ & $1.2 \pm 0.09^{\circ} 1$ & $98.6 \pm 1.4 \ddagger$ \\
\hline $\begin{array}{c}60 \\
\text { (Continuous) }\end{array}$ & 15 & $104.8 \pm 2.8 \downarrow$ & $1.8 \pm 0.6^{\circ} t$ & $0 \pm 0^{\circ} 1$ & $0 \pm 0^{\circ} 1$ & $1.9 \pm 0.2^{\circ}$ & $0 \pm 0^{\circ} 1$ & $96.8 \pm 2.2 \downarrow$ \\
\hline
\end{tabular}

Values are mean \pm SE. Successive stimuli were applied for $1 \mathrm{~min}$. Amplitude of contractions to the first, last, and the intermediate six stimuli are shown.

- Significantly different when compared to the first response $(P<0.01)$.

† Significantly different from the response at $8 / \mathrm{min}(P<0.01)$.

TABLE VII

Influence of Successive 1-s Train Duration (2.5 mA, 1-ms Pulse, at $50 \mathrm{~Hz}$ ) Stimulus on Esophageal Contractions at $5 \mathrm{~cm}$ Above LES at Different Rates (Different ISI)

\begin{tabular}{|c|c|c|c|c|c|c|c|c|}
\hline \multirow[b]{3}{*}{$\begin{array}{l}\text { Stimulus rate } \\
\text { per minute }\end{array}$} & \multirow[b]{3}{*}{$\begin{array}{c}\text { No. of } \\
\text { olservations }\end{array}$} & \multicolumn{7}{|c|}{ Amplitude of different contractions $(\mathrm{mmHg})$} \\
\hline & & \multirow[b]{2}{*}{ First } & \multicolumn{5}{|c|}{ Intermediate } & \multirow[b]{2}{*}{ Last } \\
\hline & & & 2 & 3 & 4 & 5 & 6 & \\
\hline $\begin{array}{c}8 \\
\text { (ISI, } 6.5 \mathrm{~s})\end{array}$ & 6 & $96.2 \pm 2.8$ & $98.4 \pm 4.6$ & $88.6 \pm 3.2$ & $84.2 \pm 3.8$ & $85.2 \pm 2.2$ & $86.8 \pm 2.9$ & $88.4 \pm 2.3$ \\
\hline $\begin{array}{c}10 \\
(I S I, 5 \mathrm{~s})\end{array}$ & 6 & $98.4 \pm 2.8$ & $93.2 \pm 3.2$ & $85.6 \pm 2.8^{\circ}$ & $88.4 \pm 1.4^{\circ}$ & $76.2 \pm 2.8^{\circ}$ & $78.4 \pm 3.4^{\circ} \ddagger$ & $68.0 \pm 2.6^{\circ} \ddagger$ \\
\hline $\begin{array}{r}12 \\
(\mathrm{ISI}, 4 \mathrm{~s})\end{array}$ & 9 & $94.2 \pm 2.4$ & $86.8 \pm 3.8 !$ & $12.4 \pm 1.6^{\circ} 1$ & $52.3 \pm 2.2^{\circ} \ddagger$ & $24.6 \pm 1.8^{\circ} \ddagger$ & $4.8 \pm 0.8^{\circ} \downarrow$ & $22.4 \pm 3.6^{\circ}$ \\
\hline $\begin{array}{c}15 \\
(I S I, 3 \mathrm{~s})\end{array}$ & 8 & $0 \rrbracket$ & $0^{\bullet} \ddagger$ & $2.8 \pm 0.6^{\circ} t$ & $0^{\circ} \ddagger$ & $1.6 \pm 0.4^{\circ} \ddagger$ & $0^{\circ} 1$ & $86.4 \pm 2.2^{\circ}$ \\
\hline 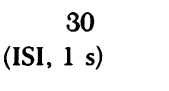 & 8 & $0 \ddagger$ & $0^{\circ} 1$ & $0^{\circ} \pm$ & $0^{\circ} 1$ & $0^{\circ} 1$ & $0^{\circ} t$ & $92.3 \pm 3.8^{\circ}$ \\
\hline $\begin{array}{c}60 \\
\text { (Continuous) }\end{array}$ & 6 & $0 \ddagger$ & $0^{\circ} \ddagger$ & $0^{\circ} \downarrow$ & 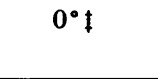 & $0^{\circ} \ddagger$ & $0^{\circ} \downarrow$ & $88.4 \pm 2.9^{\circ}$ \\
\hline
\end{tabular}

Values are mean \pm SE. Successive stimuli were applied for $1 \mathrm{~min}$. Amplitude of contractions to the first, last, and intermediate six stimuli are shown.

- Significantly different from first response $(P<0.01)$.

I Significantly different from the responses seen with $8 / \mathrm{min}$ stimulation $(P<0.01)$. 

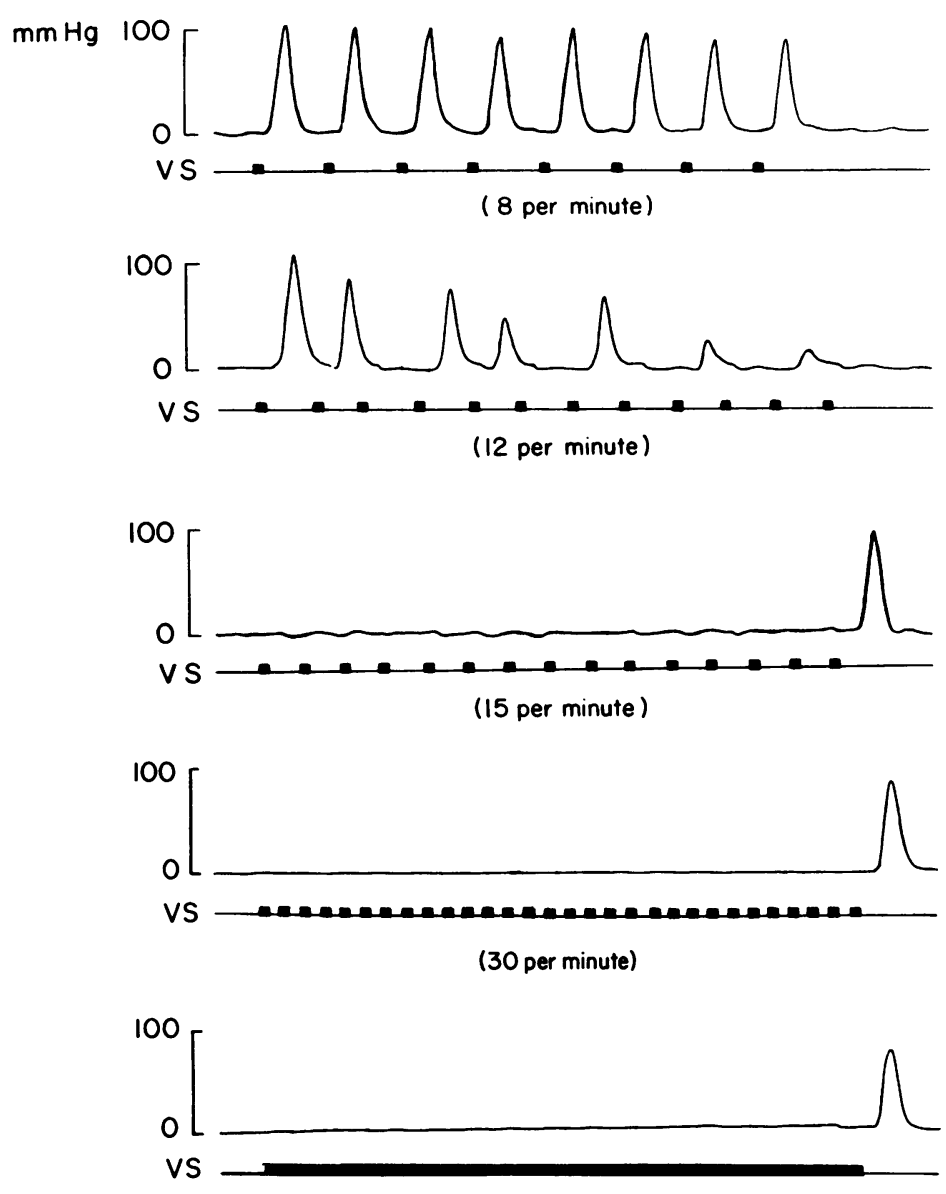

(60 per minute)

Figure 5 Influence of repetitive vagal efferent stimulation with $50 \mathrm{~Hz}$ on esophageal responses. (Other stimulus parameters-2.5 mA, $1 \mathrm{~ms}, 1-\mathrm{s}$ train). Each stimulus train was $1 \mathrm{~s}$. Note that at a rate of $8 / \mathrm{min}$, each stimulus evoked a response. However, at a rate of $12 / \mathrm{min}$ only $50 \%$ of the stimuli evoked a response. At stimulus rate of $15-60 / \mathrm{min}$ contraction to all preceding stimuli were inhibited and the response occurred only at the end of the last stimulus.

These findings may be of considerable physiological importance. For example, it is not known whether Aor B-contraction represents the physiological swallowinduced peristalsis. The B-contractions are associated with more prominent initial inhibition than the A-contractions. Observations in the literature suggest that swallows like B-contractions are associated with prominent initial inhibition (7). Myers et al. (7) have shown in humans that when two swallows are made $5 \mathrm{~s}$ apart, the second swallow inhibits the response to this first swallow. Moreover, during repetitive swallowing at short intervals $(2 \mathrm{~s})$, the esophagus remains quiescent until the last of the swallows that is followed by esophageal contraction (8). Repetitive swallows at 5-s or longer interval produce an alternate inhibited contraction or more complex pattern of inhibited responses (7). These observations support the view that B- rather than A-contractions represent normal swallowing (24). These studies, moreover, support the notion that interpretation of clinical motility records in which the patient is swallowing at close intervals should take into account these inhibitory phenomena.

It is known that swallowing is associated with descending or deglutitive inhibition. This phenomenon involves both skeletal and smooth muscle segments of the esophagus. In the skeletal muscle, deglutitive inhibition is most likely due to inhibition of vagal motor neurons in the central nervous system $(1,3,11)$. Our studies suggest that vagal efferent stimulation causes initial inhibition at the peripheral level in the smooth 
muscle. Initial inhibition may represent a mechanism of deglutitive inhibition in the smooth muscle segment of the esophagus.

The importance of refractoriness under normal physiological circumstances is not clear at the present time. However, abnormalities in the initial inhibition and refractoriness may underlie abnormal esophageal contractions that occur in patients with diffuse esophageal spasm and related esophageal motor disorders.

\section{ACKNOWLEDGMENTS}

We thank Elizabeth Howard, Donna Rao, and Kathryn VanDyke for technical assistance and Dr. Bernard Ransil for statistical advice and use of computer facilities in the Core Lab supported in part by grant RR-01032 from the General Clinical Research Centers Program of the Division of Research Resources, National Institutes of Health.

This work was supported by grant AM31092 from the National Institute of Arthritis, Metabolism, and Digestive Diseases.

\section{REFERENCES}

1. Roman, C. 1966. Controle nerveux du peristaltisme oesophagien. J. Physiol. (Paris). 58: 79-108.

2. Mukhopadhyay, A. K., and N. W. Weisbrodt. 1975. Neural organization of esophageal peristalsis: role of vagus nerve. Gastroenterology. 68: 444-447.
3. Diamant, N. E., and T. Y. El-Sharkawy. 1977. Neural control of esophageal peristalsis. A conceptual analysis. Gastroenterology. 72: 546-556.

4. Dodds, W. J., J. Christensen, J. Dent, J. D. Wood, and A. C. Arndorfer. 1978. Esophageal contractions induced by vagal stimulation in the opossum. Am. J. Physiol. 255: E392-E401.

5. Gidda, J. S., B. W. Cobb, and R. K. Goyal. 1981. Modulation of esophageal peristalsis by vagal efferent stimulation in opossum. J. Clin. Invest. 68: 1411-1419.

6. Hellemans, J., G. Vantrappen, and J. Janssens. 1974. Electromyography of the esophagus. In Diseases of the Esophagus. G. Vantrappen, editor. Springer-Verlag, New York. 282-285.

7. Meyer, G. W., D. C. Gerhardt, and D. O. Castell. 1981. Human esophageal response to rapid swallowing: muscle refractory period or neural inhibition? Am. J. Physiol. 241: G129-G136.

8. Ask, P., and L. Tibbling. 1980. Effect of time interval between swallows on esophageal peristalsis. Am. J. Physiol. 238: G485-G490.

9. Goyal, R. K., and S. Rattan. 1976. Genesis of basal sphincter pressure: effect of tetrodotoxin on lower esophageal sphincter pressure in opossum in vivo. Gastroenterology. 71: 62-67.

10. Snedecor, G. W., and W. G. Cochran. 1976. Statistical Methods. Iowa State University Press, Ames, Iowa. 258275.

11. Goyal, R. K., and B. W. Cobb. 1981. Motility of the pharynx, esophagus, and esophageal sphincters. In Physiology of the Gastrointestinal Tract. L. R. Johnson, editor. Raven Press, New York. 359-391. 